\title{
PENENTUAN JALUR TERPENDEK MENGGUNAKAN ALJABAR MIN-PLUS. Studi Kasus : Distribusi Kentang Jalur Pangalengan, Bandung - Jakarta
}

\author{
Rani Kurnia Putri \\ Program Studi Pendidikan Matematika, Fakultas Keguruan dan \\ Ilmu Pendidikan, Universitas PGRI Adi Buana Surabaya \\ email : ranikurniaputri89@gmail.com
}

\begin{abstract}
Abstrak
Penggunaan Sistem Event Diskrit (SED) dalam memodelkan, menganalisa dan mengontrol sistem-sistem yang kompleks menjadi salah satu fokus dalam dunia akademik. Gambaran karakteristik SED adalah 'kedinamikaanya' yaitu 'event driven' dimana hal tersebut bertolak belakang dengan 'time driven'. Suatu event berkaitan dengan awal atau akhir dari suatu aktifitas. Event terjadi dengan waktu diskrit, dan interval diantara event tidak harus identik (bisa deterministic atau stokastik). Aljabar Max-plus dapat menentukan dan menganalisis berbagai sifat sistem, tetapi pendekatan hanya bisa diterapkan pada sebagian klas SED, yaitu pada klas SED yang dapat diuraikan dengan model waktu invariant max-linier. Selain aljabar max-plus, dalam John and George juga disinggung beberapa varian aljabar yang serupa dengan aljabar max-plus, yaitu aljabar min-plus (dengan operasi minimum dan penjumlahan) dan aljabar max-min (dengan operasi maksimum dan minimum).

Artikel ini akan membahas tentang penentuan jalur terpendek menggunakan aljabar min-plus dengan studi kasus pada jalur distribusi kentang di pangalengan, Bandung menuju pasar Kramat jati Jakarta. Hal ini penting untuk dilakukan karena Kentang memiliki waktu kerusakan yang relatif singkat, dan kentang memiliki sifat, bila satu kentang membususk, maka kentang yang membusuk tersebut akan 'menulari' kentang yang lain, sehingga dalam waktu cepat kentang tersebut akan membusuk semuanya. Sehingga semakin cepat pendistribusian kentang sampai ke tangan konsumen akan semakin baik.
\end{abstract}

Kata kunci: Aljabar Min-Plus, Jalur Terpendek, Distribusi Kentang

\section{Pendahuluan}

Penggunaan Sistem Event Diskrit

(SED) dalam memodelkan, menganalisa dan mengontrol sistem-sistem yang kompleks menjadi salah satu fokus dalam dunia akademik. Gambaran karakteristik SED adalah 'kedinamikaanya' yaitu 'event driven' dimana hal tersebut bertolak belakang dengan 'time driven'. Suatu event berkaitan dengan awal atau akhir dari suatu aktifitas. Event terjadi dengan waktu diskrit, dan interval diantara event tidak harus identik (bisa deterministic atau stokastik). Umumnya kedinamikaan dari SED dikarakteristikkan oleh 'kesinkronan' dan 'kongruensi'. Sinkronisasi memerlukan ketersediaan dari beberapa resources pada saat yang bersamaan.. Kongruensi ada pada saat seorang pengguna harus memilih beberapa resource.

Aljabar Max-plus dapat menentukan dan menganalisis berbagai sifat sistem, tetapi pendekatan hanya bisa diterapkan pada sebagian klas SED, yaitu pada klas SED yang dapat diuraikan dengan model waktu invariant max-linier (Subiono, 2015). Selain 
aljabar max-plus, dalam John and George (2010) juga disinggung beberapa varian aljabar yang serupa dengan aljabar max-plus, yaitu aljabar min-plus (dengan operasi minimum dan penjumlahan) dan aljabar maxmin (dengan operasi maksimum dan minimum).Dalam beberapa referensi yang disebutkan diatas, telah diberikan gambaran singkat masalah-masalah yang dapat diselesaikan menggunakan aljabar max-plus yaitu masalah-masalah dalam teori graf. Seperti halnya dalam aljabar max-plus, dengan pendekatan aljabar min-plus diharapkan masalah-masalah yang terkait dapat diselesaikan.

Artikel ini akan membahas tentang penentuan jalur terpendek menggunakan aljabar min-plus dengan studi kasus pada jalur distribusi kentang di pangalengan, Bandung menuju pasar Kramat jati Jakarta. Hal ini penting untuk dilakukan karena Kentang memiliki waktu kerusakan yang relatif singkat, dan kentang memiliki sifat, bila satu kentang membususk, maka kentang yang membusuk tersebut akan 'menulari' kentang yang lain, sehingga dalam waktu cepat kentang tersebut akan membusuk semuanya.Sehingga semakin cepat pendistribusian kentang sampai ke tangan konsumen akan semakin baik.

\section{Kajian Pustaka}

\subsection{Aljabar Max-Plus (Subiono, 2015)}

Sebelum membahas mengenai aljabar minplus, terlebih dahulu diberikan definisi struktur aljabar max-plus.
Definisi 2.1.1. Definisi aljabar max-plus

Diberikan $\mathbb{R}_{\varepsilon} \stackrel{\text { def }}{=} \mathbb{R} \cup\{\varepsilon\}$ dengan $\mathbb{R}$ adalah himpunan semua bilangan real dan $\varepsilon \stackrel{\text { def }}{=}-\infty$. Pada $\mathbb{R}_{\varepsilon}$ didefinisikan operasi berikut: $\forall \mathrm{x}, \mathrm{y}$ $\in \mathbb{R}_{\varepsilon}$,

$\mathrm{x} \oplus \mathrm{y} \stackrel{\text { def }}{=} \max \{\mathrm{x}, \mathrm{y}\}$ dan $\mathrm{x} \otimes \mathrm{y} \stackrel{\text { def }}{=} \mathrm{x}+\mathrm{y}$. untuk selanjutnya operasi $\oplus$ dibaca o-plus dan operasi $\otimes$ dibaca o-times dan juga penulisan $\left(\mathbb{R}_{\varepsilon}, \oplus, \otimes\right)$ ditulis sebagai $\mathbb{R}_{\text {max }}$. Selain definisi diatas, dalam aljabar maxplus.

Definisi 2.1.2. Definisi pangkat

Untuk setiap $\mathrm{x} \in \mathbb{R}_{\max }$ dan untuk semua $\alpha \in \mathbb{R}$, maka

$$
x^{\otimes \alpha}=\alpha \times x \text {, untuk } \alpha \in \mathbb{R}
$$

\subsection{Aljabar Min-Plus (Subiono, 2015)}

Aljabar min-plus merupakan dual dari aljabar max plus, diberikan definisi aljabar min-plus.

Definisi 2.2.1. Definisi aljabar min-plus

Dual dari plus adalah minus, sehingga Aljabar min-plus didefinisikan sebagai $\mathbb{R}_{\text {min }}=\left(\mathbb{R}_{\varepsilon^{\prime}}, \oplus^{\prime}, \otimes\right)$ dimana $\mathbb{R}_{\varepsilon^{\prime}}=\mathbb{R} \cup\left\{\varepsilon^{\prime}\right\}$ dengan $\varepsilon^{\prime}=+\infty$ dan $x \oplus^{\prime} y=\min \{x, y\}$ untuk semua $x, y \in \mathbb{R}_{\varepsilon^{\prime}}$. Struktur aljabar minplus $\mathbb{R}_{\text {min }}=\left(\mathbb{R}_{\varepsilon^{\prime}}, \oplus^{\prime}, \otimes\right)$ isomorfik dengan struktur aljabar max-plus $\quad \mathbb{R}_{\max }=$ $\left(\mathbb{R}_{\varepsilon}, \oplus^{\prime}, \otimes\right)$.

Misalkan pemetaan

$$
f: \mathbb{R}_{\text {max }} \rightarrow \mathbb{R}_{\text {min }}
$$

Dengan $f(x)=-x$ untuk setiap $x \in \mathbb{R}_{\max }$.

Didapat untuk setiap $x, y \in \mathbb{R}_{\max }$ 


$$
\begin{aligned}
f(x \oplus y)=-( & x \oplus y)=-m a\{x, y\} \\
= & \min \{-x,-y\} \\
= & f(x) \oplus^{\prime} f(y)
\end{aligned}
$$

Dan

$f(x \oplus y)=-(x \oplus y)=(-x)+(-y)=$ $f(x) \oplus f(y)$.

Jelas bahwa pemetaan $f$ adalah bijektif.

\subsection{Vektor dan Matriks dalam Aljabar}

\section{Max-Plus}

Himpunan matriks $\mathrm{n} \times \mathrm{m}$ dalam aljabar maxplus dinyatakan dalam $\mathbb{R}_{\max }^{n \times m}$. Didefinisikan $\mathrm{n}=\{1,2,3, \ldots, \mathrm{n}\}$, untuk $\mathrm{n} \in \mathbb{N}$. Elemen dari matriks $\mathbb{R}_{\text {max }}^{n \times m}$ pada baris ke- $i$ kolom ke- $j$ dinyatakan dengan $a_{\mathrm{ij}}$ untuk $i \in \mathrm{n}$ dan $j \in \mathrm{m}$. Dalam hal ini matriks A dapat dituliskan sebagai

$$
A=\left[\begin{array}{cccc}
a_{1,1} & a_{1,2} & \ldots & a_{1, m} \\
a_{2,1} & a_{2,2} & \ldots & a_{2, m} \\
\vdots & \vdots & \ddots & \vdots \\
a_{4,1} & a_{4,2} & \ldots & a_{n, m}
\end{array}\right]
$$

ada kalanya elemen $a_{\mathrm{ij}}$ juga dinotasikan sebagai

$$
[A]_{i, j}, i \in n, j \in m
$$

Untuk matriks $\mathrm{A}, \mathrm{B} \in \mathbb{R}_{\max }^{n \times m}$ penjumlahan matriks $\mathrm{A} \oplus \mathrm{B}$ didefinisikan sebagai

$$
[A+B]_{i, j}=a_{i, j} \oplus b_{i, j}
$$

Untuk $i \in n$ dan $j \in m$. Catatan bahwa, untuk $\mathrm{A}, \mathrm{B} \in \mathbb{R}_{\max }^{n \times m}$ berlaku bahwa $\mathrm{A} \oplus \mathrm{B}=$ $\mathrm{B} \oplus \mathrm{A}, \quad$ sebab $[\mathrm{A} \oplus \mathrm{B}]_{\mathrm{ij}}=\max \left\{a_{i, j}, b_{i, j}\right\}=$ $\max \left\{b_{i, j}, a_{i, j}\right\}=[\mathrm{B} \oplus \mathrm{A}]_{\mathrm{ij}}$, untuk $\mathrm{i} \in \mathrm{n} \operatorname{dan} j$ $\in \mathrm{m}$.

Untuk A $\in \mathbb{R}_{\max }^{n \times m}$ dan skalar $\alpha \in \mathbb{R}_{\max }$ perkalian dengan skalar didefinisikan sebagai berikut

$[\alpha \otimes A]_{i, j}=\alpha \otimes a_{i, j}$, untuk $i \in n$ dan $j \in m$.
Dan untuk matriks $\mathrm{A} \in \mathbb{R}_{\text {max }}^{n \times p}$ dan $\mathrm{B} \in \mathbb{R}_{\text {max }}^{p \times m}$ perkaliaan $\mathrm{A} \otimes \mathrm{B}$ didefinisikan sebagai berikut:

$$
[\alpha \otimes B]_{i, j}=\underset{k=1}{p} \oplus a_{i, k} \otimes b_{k, j}
$$

\subsection{Nilai Eigen dan Vektor Eigen}

Pengertian nilai eigen (eigenvalue) dan vektor eigen (eigenvector) yang bersesuaian dari suatu matriks persegi A berukuran $n \times n$ sebagaimana dijumpai dalam aljabar linier biasa, juga dijumpai dalam aljabar max-plus, yaitu bila diberikan suatu persamaan

$$
A \otimes x=\lambda \otimes x
$$

Dalam hal ini masing - masing vektor $\mathrm{x} \in$ $\mathbb{R}_{\text {max }}^{n}$ dan $\lambda \in \mathbb{R}$, dinamakan vektor eigen dan nilai eigen dari matriks A dengan vektor $\mathrm{x} \neq(\varepsilon, \cdots, \varepsilon)^{\mathrm{T}}$.

\subsection{Matriks dan Graf (Subiono, 2015)}

Misalkan diberikan matriks $A \in \mathbb{R}_{\max }^{n x n}$ suatu graf berarah dari matriks Aadalah $\mathcal{G}(A)=(E, V)$. Graf $\mathcal{G}(A)$ mempunyai $n$ titik, dan himpunan semua titik dari $\mathcal{G}(A)$ dinyatakan oleh $V$. Suatu garis dari titik $j$ ke titik $i$ ada bila $a_{i j} \neq \varepsilon$, garis ini dinotasikan oleh $(j, i)$ dengan demikian $(j, i) \in \mathcal{D}$. Bobot dari garis $(j, i)$ adalah nilai dari $a_{i, j}$ yang dinotasikan oleh $w(j, i)=a_{i, j} \in \mathbb{R}_{\max }$. Bila $a_{i j}=\varepsilon$, maka garis $(j, i)$ tidak ada.

$$
\text { Suatu barisan garis }\left(i_{1}, i_{2}\right) \text {, }
$$
$\left(i_{2}, i_{3}\right), \ldots,\left(i_{l-1}, i_{l}\right) \quad$ dari suatu graf dinamakan suatu path. Suatu path dikatakan elementer bila tidak ada titik terjadi dua kali dalam path tersebut. Suatu sirkuit adalah path elementer tertutup, yaitu $\left(i_{1}, i_{2}\right)$, 
$\left(i_{2}, i_{3}\right), \ldots,\left(i_{l-1}, i_{l}\right) . \quad$ Bobot dari suatu pathp $=\left(i_{1}, i_{2}\right), \quad\left(i_{2}, i_{3}\right), \ldots,\left(i_{l-1}, i_{l}\right)$ dinotasikan $|p|_{w}$ dan diberikan oleh $|p|_{w}=$ $w\left(i_{1}, i_{2}\right)+w\left(i_{2}, i_{3}\right)+\cdots+w\left(i_{l-1}, i_{l}\right)=$ $\left(a_{i 2, i 2}+a_{i 3, i 2}+\cdots+a_{i, i_{l-1}}\right), \quad$ sedangkan panjang dari pathp atau banyaknya garis dalam path $p$ dinotasikan oleh $|p|_{l}$. Himpunan semua path dari titik $i$ ke titik $j$ dengan panjang $k$ dinotasikan oleh $P(j, i ; k)$. Bobot rata-rata dari pathp adalah bobot dari $p$ dibagi oleh banyaknya garis dalam pathp, yaitu:

$$
\frac{|p|_{w}}{|p|_{l}}=\frac{\left(a_{i 2, i 2}+a_{i 3, i 2}+\cdots+a_{i, i_{l-1}}\right)}{(l-1)}
$$

Teori 2.5.1 Misalkan matriks A berukuran $n x n$. Graf $\mathcal{G}(A)$ tidak memuat sirkuit bila dan hanya bila $A^{\oplus k}=\varepsilon(n, n), \quad \forall k \geq n$.

\section{Metode Penelitian}

\subsection{Tempat Penelitian}

Penelitian ini dilaksanakan di Desa Pulosari Kecamatan pangalengan Kabupaten Bandung Provinsi Jawa Barat.

\subsection{Tahapan Penelitian}

Adapun tahapan-tahapan penelitiannya sebagai berikut:

a. Studi literatur dan pengumpulan ata

b. Mengkaji dan menganalisis model matematika Aljabar Min-Plus

c. Merumuskan Penyelesaian Numerik.

d. Analisa hasil dan pembahasan Pada tahapan ini hasil yang telah diperoleh dianalisis untuk kemudian diambil kesimpulan

e. Simpulan

\section{Hasil dan Pembahasan}

\subsection{Jalur Pangalengan- Pasar Induk} Kramat Jati Jakarta

Jalur tempuh untuk mendistribusikan kentangdaripangalengan, kabupaten bandungmenuju PasarKramatjatiJakartaPusat dapat melalui beberapadaerahyangberbeda. ruteruteperjalanannyadapat dilihat dalam tabeltabel dibawah ini.

Tabel 1. Tabel Jalur Tempuh Melalui Jalan Tol Cipularang dan Jalur Pantura

\begin{tabular}{|l|l|l|}
\hline \multicolumn{3}{|c|}{ Melalui JalanTol Cipularang danJalurPantura/ JalanTolJakarta-Cikampek } \\
\hline No & Jaluryang dilalui & \multicolumn{1}{c|}{ JarakTempuh } \\
\hline 1 & $\begin{array}{l}\text { Jalan rayapangalengan, jalangandasari, } \\
\text { jalan soreangkopo, jalanrayakopo sayati }\end{array}$ & $37,3 \mathrm{~km}$ (1 jam19 menit) $)$ \\
\hline 2 & $\begin{array}{l}\text { Jalan tol cipularangdan jalurpantura, } \\
\text { jalan tolJakarta-cikampek, jalan T.B. } \\
\text { Simatupang, Cijantung/Kramat } \\
\text { Jati/Cililitan }\end{array}$ & $141 \mathrm{~km}$ (1 jam56 menit) \\
\hline 3 & Jalan rayabogor, jalan pedati, jalan H. \\
& Taiman Ujung & $2,5 \mathrm{~km}$ (8menit) \\
\hline 4 & \multicolumn{2}{|c|}{ DESTINASI } \\
\hline
\end{tabular}


Tabel 2. Tabel Jalur Tempuh melalui Jalan Raya Cianjur - Ciawi

\begin{tabular}{|c|c|c|}
\hline \multicolumn{3}{|c|}{ Melalui JalanRaya Ciawi-Cianjur } \\
\hline No & Jaluryang dilalui & JarakTempuh \\
\hline 1 & $\begin{array}{l}\text { Jalan rayapangalengan, jalangandasari, } \\
\text { jalan rayasoreangkopo, Jalan rayakopo } \\
\text { sayati }\end{array}$ & $37,3 \mathrm{~km}$ (1 jam19 menit) \\
\hline 2 & $\begin{array}{l}\text { Jalan tol padaleunyi dan jalan nasionalIII } \\
\text { kejalanIr.H. Djuanda/ JalanLabuan- } \\
\text { Cianjur/Jalan RayaCiawi-Cianjur/ Jalan } \\
\text { RayaPuncak- Cianjur }\end{array}$ & $60,9 \mathrm{~km}$ (1 jam34 menit) \\
\hline 3 & Bogor & $48,7 \mathrm{~km}$ (1 jam47 menit) \\
\hline 4 & $\begin{array}{l}\text { Jalan tol jagorawi, jalanpondok gede } \\
\text { (Jakartatimur) }\end{array}$ & $41,6 \mathrm{~km}$ (33menit) \\
\hline 5 & $\begin{array}{l}\text { Jalan pondok gede, Jalanrayabogor, } \\
\text { jalan merpatidan jalan kramat utaradari } \\
\text { jalan H.Taiman Ujung }\end{array}$ & $2,2 \mathrm{~km}$ (8menit) \\
\hline 6 & DES & NASI \\
\hline
\end{tabular}

Tabel 3. Tabel Jalur Tempuh Melalui Jalan Nasional III

\begin{tabular}{|l|l|l|}
\hline \multicolumn{2}{|c|}{ Melalui JalanNasionalIII } \\
\hline No & \multicolumn{1}{|c|}{ Jaluryang dilalui } & \multicolumn{1}{|c|}{ JarakTempuh } \\
\hline 1 & $\begin{array}{l}\text { Jalan rayapangalengan, jalan situ } \\
\text { cileunca, jalanrayapangalengan, Tangu, } \\
\text { Kebon kelapa, jalan pahlawan, dangdeur, } \\
\text { jalan rayakamasan banjaran, jalan } \\
\text { gandasari/kebun kelapa, jalan raya } \\
\text { soreangkopo/jalan terusan kopo, jalan } \\
\text { rayakopo sayati, jalan rayakopo, jalan } \\
\text { keluartolpasir koja, jalan tolpadaleunyi, } \\
\text { padalarang/cianjur/sukabumi, jalan } \\
\text { nasionalIII, Jalan Parahyangan, Jalan } \\
\text { nasionalIII, jalan rayacibogo, jalan } \\
\text { mekargalih, jalanrayacariu, jalan raya } \\
\text { jonggolcariu, }\end{array}$ \\
\hline 2 & $\begin{array}{l}\text { Jalan rayainpres, jalan merpati, jalan } \\
\text { kramat utara, jalan H.Taiman ujung }\end{array}$ & $180 \mathrm{~km}$ (1,1 km(4menit) \\
\hline
\end{tabular}


3

\subsection{Penentun Lintasan Terpendek Menggunakan Aljabar Min-Plus}

Masalahpenentuanjalurterpendekrute Pangalenganbandung menuju Pasar Induk Kramat jati, bersifat sekali jalan (oneway). Perjalanan Pangalengan-Jakarta dapatditempuhmelaluitigapilihanrute, yaitu melalui

Melalui

JalanTolCipularang,melalui JalanRaya

Ciawi-Cianjur,danyang terakhir melaluiJalan

NasionalIII.Setiapjaluryangdipilih,memilik iwaktu tempuhyangberbeda-beda.

Ruteyang ditempuhakan dimodelkan kedalambentukjaringan proyek sehinggamemudahkanperhitungan pencarianjalurterpendekmenggunakan aljabar $\min -$ plus.Dalamjaringanproyekini,titikmenyatak anpersimpangan jalan, busur menyatakansuatu jalan, sedangkan bobotbusur menyatakanwaktu tempuh, sehinggabobotbusur akan selalu bernilai positif.

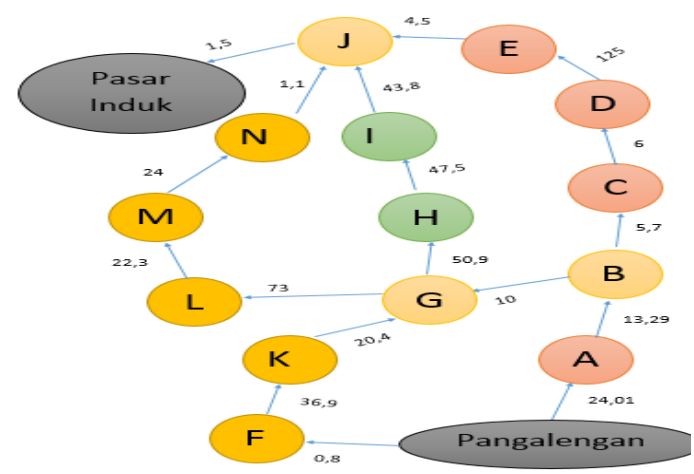

\section{DESTINASI} menggunakan aljabar min-plus, jaringan proyek diatas dapat diubah menjadi:

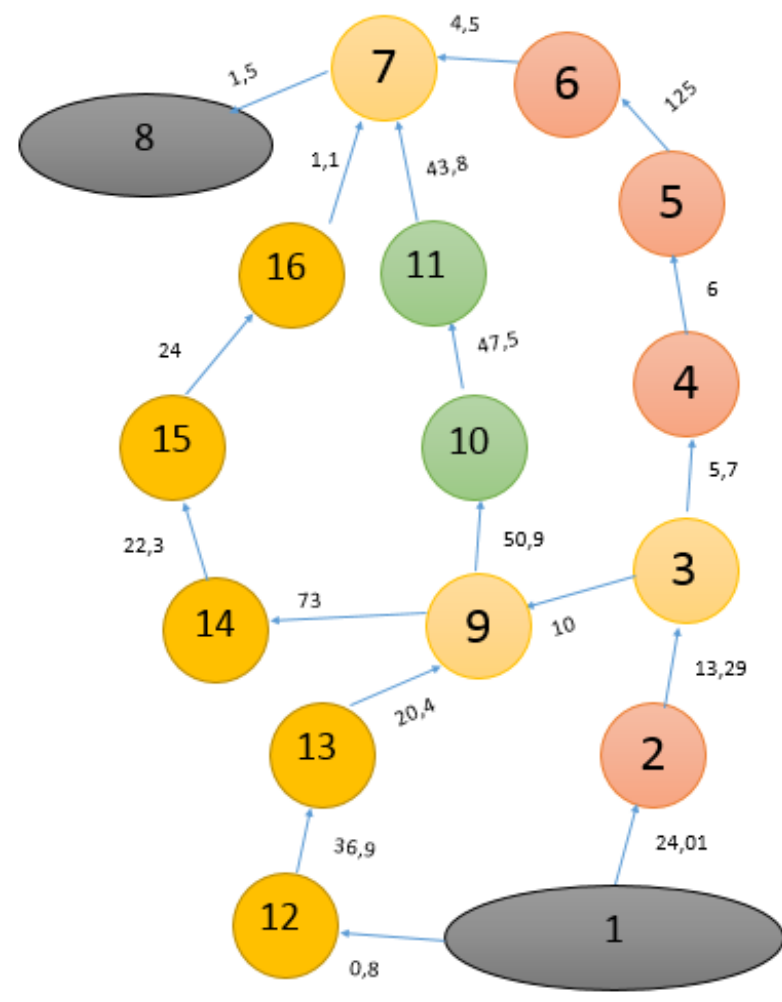


Jaringan proyek berbentuk graf dapat diubah menjadi bentuk matriks sebagai berikut:

\begin{tabular}{|c|c|c|c|c|c|c|c|c|c|c|c|c|c|c|c|}
\hline$\varepsilon$ & $\varepsilon$ & $\varepsilon$ & $\varepsilon$ & $\varepsilon$ & $\varepsilon$ & $\varepsilon$ & $\varepsilon$ & $\varepsilon$ & $\varepsilon$ & $\varepsilon$ & $\varepsilon$ & $\varepsilon$ & $\varepsilon$ & $\varepsilon$ & $\varepsilon$ \\
\hline 24,01 & $\varepsilon$ & $\varepsilon$ & $\varepsilon$ & $\varepsilon$ & $\varepsilon$ & $\varepsilon$ & $\varepsilon$ & $\varepsilon$ & $\varepsilon$ & $\varepsilon$ & $\varepsilon$ & $\varepsilon$ & $\varepsilon$ & $\varepsilon$ & $\varepsilon$ \\
\hline$\varepsilon$ & 13,29 & $\varepsilon$ & $\varepsilon$ & $\varepsilon$ & $\varepsilon$ & $\varepsilon$ & $\varepsilon$ & $\varepsilon$ & $\varepsilon$ & $\varepsilon$ & $\varepsilon$ & $\varepsilon$ & $\varepsilon$ & $\varepsilon$ & $\varepsilon$ \\
\hline$\varepsilon$ & $\varepsilon$ & 5,7 & $\varepsilon$ & $\varepsilon$ & $\varepsilon$ & $\varepsilon$ & $\varepsilon$ & $\varepsilon$ & $\varepsilon$ & $\varepsilon$ & $\varepsilon$ & $\varepsilon$ & $\varepsilon$ & $\varepsilon$ & $\varepsilon$ \\
\hline$\varepsilon$ & $\varepsilon$ & $\varepsilon$ & 6 & $\varepsilon$ & $\varepsilon$ & $\varepsilon$ & $\varepsilon$ & $\varepsilon$ & $\varepsilon$ & $\varepsilon$ & $\varepsilon$ & $\varepsilon$ & $\varepsilon$ & $\varepsilon$ & $\varepsilon$ \\
\hline$\varepsilon$ & $\varepsilon$ & $\varepsilon$ & $\varepsilon$ & 125 & $\varepsilon$ & $\varepsilon$ & $\varepsilon$ & $\varepsilon$ & $\varepsilon$ & $\varepsilon$ & $\varepsilon$ & $\varepsilon$ & $\varepsilon$ & $\varepsilon$ & $\varepsilon$ \\
\hline$\varepsilon$ & $\varepsilon$ & $\varepsilon$ & $\varepsilon$ & $\varepsilon$ & 4,5 & $\varepsilon$ & $\varepsilon$ & $\varepsilon$ & $\varepsilon$ & 43,8 & $\varepsilon$ & $\varepsilon$ & $\varepsilon$ & $\varepsilon$ & 1,1 \\
\hline$\varepsilon$ & $\varepsilon$ & $\varepsilon$ & $\varepsilon$ & $\varepsilon$ & $\varepsilon$ & 1,5 & $\varepsilon$ & $\varepsilon$ & $\varepsilon$ & $\varepsilon$ & $\varepsilon$ & $\varepsilon$ & $\varepsilon$ & $\varepsilon$ & $\varepsilon$ \\
\hline$\varepsilon$ & $\varepsilon$ & $\varepsilon$ & $\varepsilon$ & $\varepsilon$ & $\varepsilon$ & $\varepsilon$ & $\varepsilon$ & $\varepsilon$ & $\varepsilon$ & $\varepsilon$ & $\varepsilon$ & 20,4 & $\varepsilon$ & $\varepsilon$ & $\varepsilon$ \\
\hline$\varepsilon$ & $\varepsilon$ & 10 & $\varepsilon$ & $\varepsilon$ & $\varepsilon$ & $\varepsilon$ & $\varepsilon$ & 50,9 & $\varepsilon$ & $\varepsilon$ & $\varepsilon$ & $\varepsilon$ & $\varepsilon$ & $\varepsilon$ & $\varepsilon$ \\
\hline$\varepsilon$ & $\varepsilon$ & $\varepsilon$ & $\varepsilon$ & $\varepsilon$ & $\varepsilon$ & $\varepsilon$ & $\varepsilon$ & $\varepsilon$ & 47,5 & $\varepsilon$ & $\varepsilon$ & $\varepsilon$ & $\varepsilon$ & $\varepsilon$ & $\varepsilon$ \\
\hline 0,8 & $\varepsilon$ & $\varepsilon$ & $\varepsilon$ & $\varepsilon$ & $\varepsilon$ & $\varepsilon$ & $\varepsilon$ & $\varepsilon$ & $\varepsilon$ & $\varepsilon$ & $\varepsilon$ & $\varepsilon$ & $\varepsilon$ & $\varepsilon$ & $\varepsilon$ \\
\hline$\varepsilon$ & $\varepsilon$ & $\varepsilon$ & $\varepsilon$ & $\varepsilon$ & $\varepsilon$ & $\varepsilon$ & $\varepsilon$ & $\varepsilon$ & $\varepsilon$ & $\varepsilon$ & 36,9 & $\varepsilon$ & $\varepsilon$ & $\varepsilon$ & $\varepsilon$ \\
\hline$\varepsilon$ & $\varepsilon$ & $\varepsilon$ & $\varepsilon$ & $\varepsilon$ & $\varepsilon$ & $\varepsilon$ & $\varepsilon$ & 73 & $\varepsilon$ & $\varepsilon$ & $\varepsilon$ & $\varepsilon$ & $\varepsilon$ & $\varepsilon$ & $\varepsilon$ \\
\hline$\varepsilon$ & $\varepsilon$ & $\varepsilon$ & $\varepsilon$ & $\varepsilon$ & $\varepsilon$ & $\varepsilon$ & $\varepsilon$ & $\varepsilon$ & $\varepsilon$ & $\varepsilon$ & $\varepsilon$ & $\varepsilon$ & 22,3 & $\varepsilon$ & $\varepsilon$ \\
\hline$\varepsilon$ & $\varepsilon$ & $\varepsilon$ & $\varepsilon$ & $\varepsilon$ & $\varepsilon$ & $\varepsilon$ & $\varepsilon$ & $\varepsilon$ & $\varepsilon$ & $\varepsilon$ & $\varepsilon$ & $\varepsilon$ & $\varepsilon$ & 24 & $\varepsilon$ \\
\hline
\end{tabular}

Arti dari matriks tersebut adalah untuk matriks A pada baris 1 kolom 1 bernilai $\varepsilon$ atau $+\infty$. Dengan kata lain tidak ada rute perjalanan pada graf tersebut. Rute tersebut dapat dinyatakan sebagai $A(1,1)=\varepsilon$, begitu pula seterusnya untuk baris dan kolom yang lain.

Untuk mendapatkan jalur optimal menggunakan Aljabar Min-Plus diperlukan perhitungan matriks $A^{*}$. Matriks $A^{*}$ diperoleh dari dari $A^{*}=A^{\otimes(k-1)}=$ $A \oplus^{\prime} A^{2} \oplus^{\prime} A^{3} \oplus^{\prime} \ldots \oplus^{\prime} A^{16}$.

Penyelesaian perhitungan matriks berukuran 16 kali 16 tersebut akan sukar dilakukan dengan perhitungan manual, sehingga akan dilakukan secara numerik menggunakan software scilab.

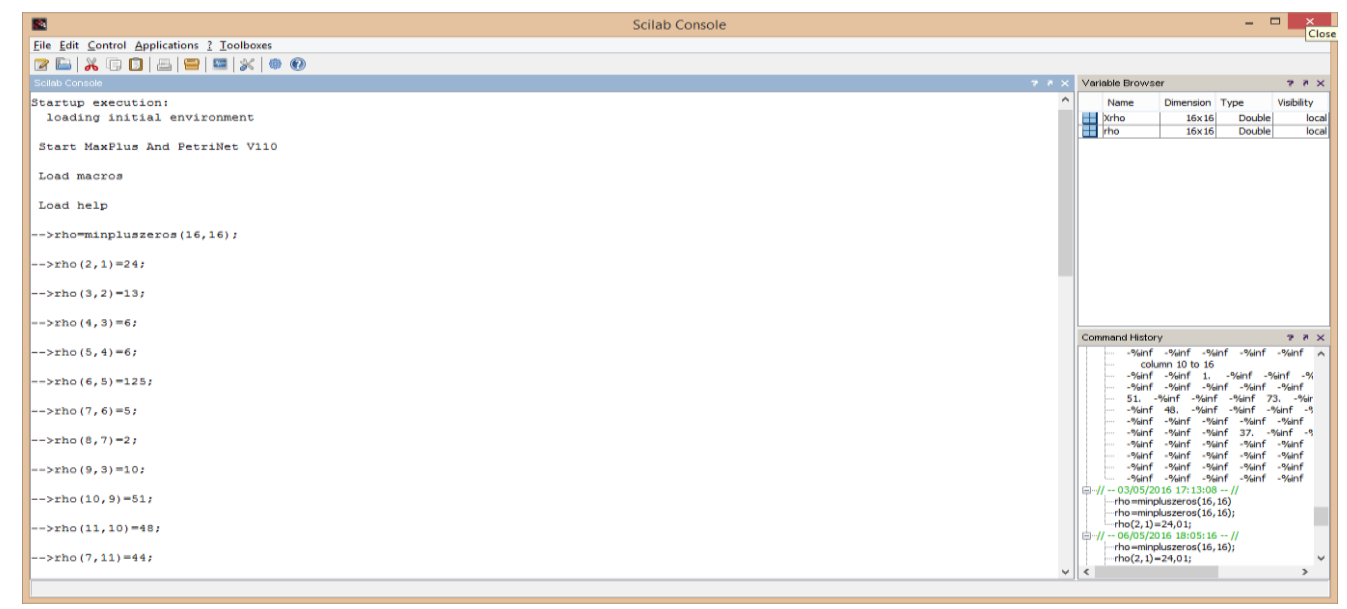



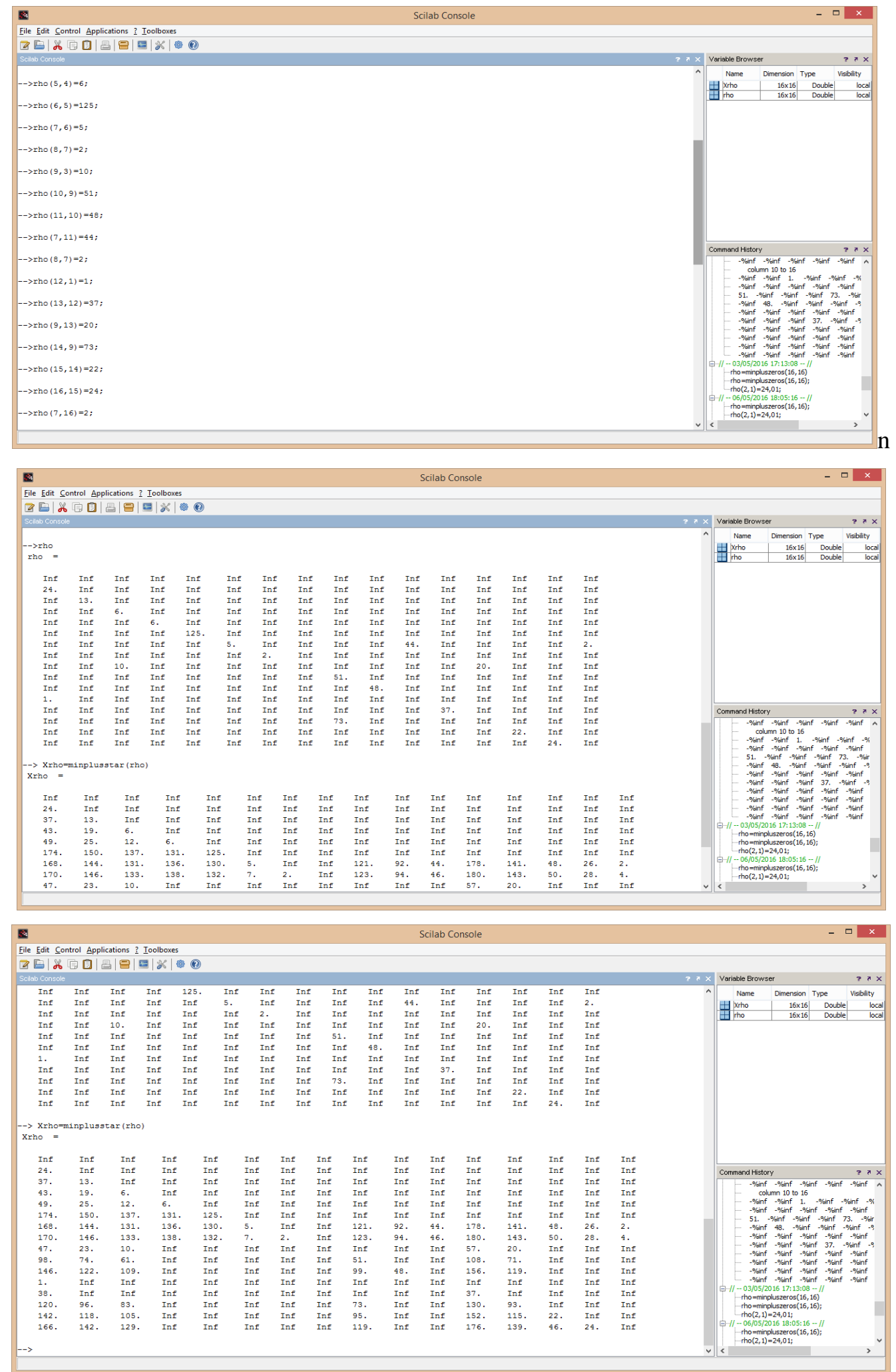

Hasil perhitungan menggunakan software Scilab yang disinkronisasi dengan toolbox MAXPLUSV16072014, diperoleh nilai-nilai yang optimal pada Matriks $A^{*}$, dimana hal tersebut dapat disimpulkan bahwa distribusi kentang dari PangalenganBandung menuju pasar Kramat Jati-Jakarta ditempuh dengan jarak yang minimum yaitu $166 \mathrm{~km}$. Dalam hal ini ditunjukkan pada 
matriks $A^{*}(16,1)$. Artinya rute awal berada di state 1 dan berakhir di state 16 dengan jalur yang di lalui yaitu:

\begin{tabular}{|l|}
\hline Jalan raya pangalengan, jalan gandasari, \\
jalan soreang kopo, jalan raya kopo sayati, \\
jalan raya kopo, jalan keluar tol pasir koja, \\
jalan tol padaleunyi, \\
padalarang/cianjur/sukabumi, jalan \\
nasional III, Jalan Parahyangan, Jalan \\
nasional III, jalan raya cibogo, jalan mekar \\
galih, jalan rayacariu, jalan raya \\
jonggolcariu, Jalan raya inpres, jalan \\
merpati, jalan kramat utara, jalan H.Taiman \\
ujung, DESTINASI
\end{tabular}

\section{KESIMPULAN}

Kesimpulan yang diperoleh dalam penelitian ini adalah:

1. Model sistem jaringan didasarkan pada model graf berarah yang perhitungan jalur terpendeknya disesuaikan dengan perhitungan aljabar min-plus

2. Jalur terpendek yang diperoleh untuk jalur distribusi kentang menggunakan perhitungan aljabar min-plus adalah sepanjang $166 \mathrm{~km}$, diawali di Jalan Raya Pangalengan dan berakhir di Jalan H.Taiman Ujung.

\section{DAFTAR PUSTAKA}

[1] Adzkiya, Dieky, 2009, Membangun Model Petri Net Lampu Lalu Lintas dan Simulasinya, Tesis Magister Matematika, Istitut Sepuluh Nopember, Surabaya.
[2] Andersen, M.H., 2002, Max-Plus Algebra: Properties And Applications, Master of Science in Mathematic Thesis Department of Mathematics, Laramie, WY.

[3] John S. Baras and George

Theodorakopoulos. 2010. Path

Problems in Networks. Synthesis

Lectures on Communication

Networks. Morgan \& Claypool

Publishers.

[4] Kentang Pangalengan dan Kertasari Bandung Jadi Komoditi Ekspor, 2013, www.fokusjabar.com.

[5] Rudhito, Andy, 2013, Sistem Persamaan Linear Min-Plus dan Penerapannya pada Masalah Lintasan Terpendek, Prosiding, FMIPA UNY Yogyakarta [6] Subiono, 2015, Aljabar Max Min-plus dan Terapannya, Buku Ajar Aljabar Max-plus, Institut Sepuluh Nopember, Surabaya. 